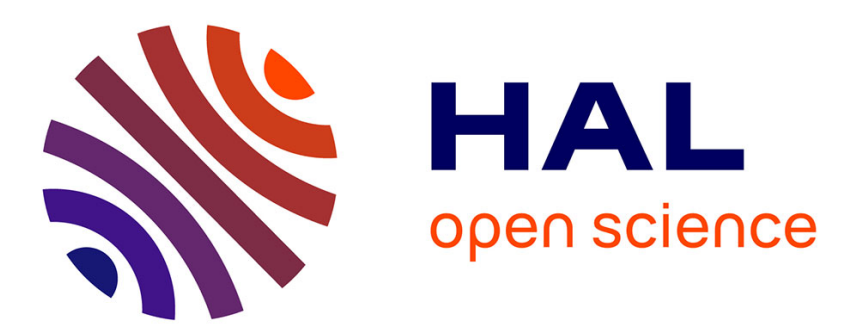

\title{
Behaviour of Crack-Rate Sensitive Brittle Materials in Dynamic Lateral Compression
}

\author{
H. Kobayashi, M. Daimaruya
}

\section{To cite this version:}

H. Kobayashi, M. Daimaruya. Behaviour of Crack-Rate Sensitive Brittle Materials in Dynamic Lateral Compression. Journal de Physique IV Proceedings, 1997, 07 (C3), pp.C3-987-C3-992. 10.1051/jp4:19973166 . jpa-00255456

\section{HAL Id: jpa-00255456 https://hal.science/jpa-00255456}

Submitted on 1 Jan 1997

HAL is a multi-disciplinary open access archive for the deposit and dissemination of scientific research documents, whether they are published or not. The documents may come from teaching and research institutions in France or abroad, or from public or private research centers.
L'archive ouverte pluridisciplinaire HAL, est destinée au dépôt et à la diffusion de documents scientifiques de niveau recherche, publiés ou non, émanant des établissements d'enseignement et de recherche français ou étrangers, des laboratoires publics ou privés. 
J. PHYS IV FRANCE 7 (1997)

Colloque C3, Supplément au Journal de Physique III d'août 1997

\title{
Behaviour of Crack-Rate Sensitive Brittle Materials in Dynamic Lateral Compression
}

\author{
H. Kobayashi and M. Daimaruya \\ Department of Mechanical Systems Engineering, Muroran Institute of Technology, 27-1 Mizumoto, \\ Muroran, Hokkaido 050, Japan
}

\begin{abstract}
In order to investigate the behaviour of brittle tubular materials in static and dynamic lateral compression tests (LC tests), an analytical technique including crack-rate sensitjvity of brittle materials was applied. From the analysis, it was found that the maximum load, $P_{\mathrm{n} 1 \mathrm{x}}$, in LC tests increases with the increase of the loading rate and this tendency is more remarkable when the crack-rate sensitivity of a brittle material is large. The results from dynamic and static experiments using a mullite ceramic tubes support reasonably the results obtained from the analysis

Résumé : Dans le but d'etudier le comportement des matériaux fragiles en forme de tube, en essais de compression latérale(essais $\mathrm{CL}$ ) en estimation statique et dynamique, une technique analytique incluse la sensibilité de la vélocité de la fissure des matériaux fragiles a été appliqueé. Du point de vae de l'analyse, il a été observé que la charge maximale. $P_{\max }$ en essais CL croit avec l'augmentation de la vitesse du chargement. Cette tendance est plus remarquable quand la sensibilité de la vitesse de la fissure des matériaux fragiles est grande. Les résultats expérimentaux obtenus à partir de l'estimation statique et dynamique en utilisant les tubes en céramique-mullite, supportent bien les résultats obtenus à partir de l'analyse.
\end{abstract}

\section{INTRODUCTION}

It has been observed that the fracture toughness value, $K_{\mathrm{I}}$, of ceramics and glasses considerably depend on crack velocity, $\dot{a}$. This is appeared to be caused by the stress corrosion due to water in the environment. In glasses and some oxide ceramics, therefore, $\dot{a}-K_{1}$ relation, which are often given by $\dot{a}=C \cdot K_{1}{ }^{n}$, has been obtained experimentally by using various type of specimens such as double cantilever beam (DCB) or double torsion (DT) specimens [1-4]. Recently, an analysis including this crack-rate effect was proposed and applied to a number of tests, e.g. three-point bending(3PB) and single edge cracked tension(SECT). From these analytical and experimental studies[5-8], a number of interesting facts were clarifjed, e.g. pseudo stable phenomenon, which is the phenomenon that crack extension occurs before the load reaches the maximum, and the effects of specimen geometry on $K_{\mathrm{I}}$ value which were examined by using 3PB, SECT and compact tension (CT) specimens. It has been mentioned that the crack-rate effect appears in conventional fracture toughness tests for crack-rate sensitive, perfectly brittle materials.

While, the lateral compression (LC) test of circular tubes sandwiched by two rigid plates [9] is one of the useful testing methods to investigate the strength of brittle materials[10]. Because the specimen for this test is quite simple and the influence of friction between a specimen and rigid compression plates is small. Therefore, it would be a very convenient method to examine the effect of crack-rate sensitivity on the mechanical properties of brittle materials.

In this study, as the first step, lateral compression tests for pre-cracked circular tubes of brittle materials was considered. The analysis taking account of crack-rate sensitivity was applied to examine the effects of initial crack length and loading rate on the behaviour of circular tubes in LC tests. Then, the load-deflection curves of specimens without any initial cracks were calculated by regarding them as specimens with very small cracks. A series of dynamic $L C$ cests using Hopkinson pressure bar technique and quasi-static tests were performed for a mullite ceramic tube. The increase of the maximum load in LC 
tests due to the increase of the loading rate was discussed in relation to the crack-rate sensitivity of perfectly brittle materials.

\section{NUMERICAL ANALYSIS}

It is often mentioned that the strength of ceramics and glasses depends on loading rate as same as many metals[11]. This dependence may have a certain relation to the crack-rate sensitivity of brittle materials. Therefore, an analysis including crack-rate sensitivity may be quite useful for the investigation of the loading rate effect of brittle materials.

\subsection{Load and deflection of circular tube in lateral compression}

Let us consider lateral compression tests of a circular specimen with two pre-cracks (initial length : $a_{0}$ ), as shown in Fig. 1. The

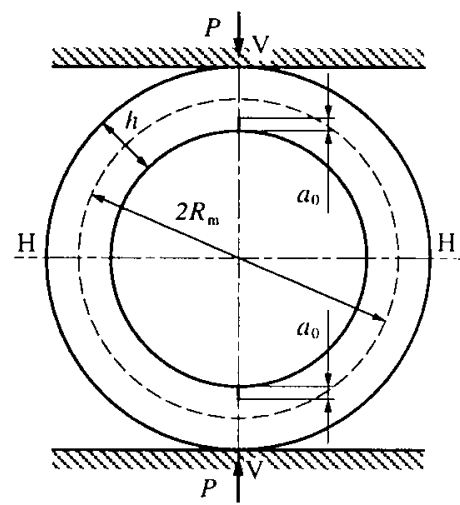

Fig. I Circular tube specimen with a pair of cracks in lateral compression tests

The length, mean radius and wall-thickness of the tubular specimen are $L, R_{\mathrm{m}}$ and $h$, respectively. If a quasi-static crack extension (kinetic energy $=0$ ) can be assumed during the tests, the relations among the deflection, $\delta$, the applied load, $P$, and the energy release rate, $G$, are given by

$$
\delta=P\{\lambda(A)+\Lambda\}, \quad G=\left(P^{2} / 2\right)(d \lambda d d A)
$$

where $\lambda(A)$ and $\Lambda$ are the compliances of the specimen and of the testing machine, respectively. $A$ is the cracked area and equal to $L a$ ( $a$ : crack length). In perfectly brittle and crack-rate sensitive materials, the crack resistance force, $R$, is assumed to be given by $R=R_{0}\left(\dot{a} / \dot{a}^{*}\right)^{m}$, where $\dot{a}$ is crack extension rate, $\dot{a}^{*}$ is an arbitrary reference crack extension rate, $m$ is rate sensitivity parameter and $R_{0}$ is a constant for perfectly brittle materials. Putting $R=G, \delta$ can be written as follows :

$$
\delta=\delta_{0}(a) \cdot\left(\frac{\dot{a}}{\dot{a}^{*}}\right)^{m / 2}, \quad \delta_{0}(a)=\sqrt{\frac{2 L R_{0}}{(d \lambda / d a)}}\{\lambda(a)+\Lambda\}
$$

where $\delta_{0}(a)$ corresponds to the deftection in the case of crack-rate insensitive materials $(m=0)$. In constant velocity tests, $\delta=V_{0} l$, where $V_{0}$ is a constant testing velocity and $t$ is time. From equ.(2), $\delta^{2}=$ $\delta_{0}{ }^{2} \cdot\left(a / a^{*}\right)^{m}=\left(V_{0} t\right)^{2}$ is given, therefore, the following equation can be derived:

$$
a^{*}\left(V_{0} t\right)^{2 / m} d t=\left\{\delta_{0}(a)\right\}^{2 / m} d a
$$

By integrating both members of equ.(3), the $\delta$ and $P$ can be obtained as follows:

$$
\delta=\left\{\left(\frac{V_{0}}{a^{*}}\right)\left(\frac{m+2}{m}\right) \int_{a_{1,}}^{a} \delta_{0}{ }^{2{ }^{\prime \prime m}} d a\right\}^{\frac{m}{m+2}}, \quad P=\frac{\delta}{\lambda+\Lambda}
$$

Equ.(4) includes testing velocity and crack rate sensitivity parameter, therefore, the effect of these parameters on $P-\delta$ curves and the maximum load, $P_{\max }$, can be examined.

\subsection{Non-dimensional values and compliance of specimen}

In actual numerical calculations, non-dimensional load, $P^{*}$, deflection, $\delta^{*}$, compliance, $\lambda^{*}$, and testing velocity, $V_{0}{ }^{*}$, are used, as shown below:

$$
P^{*}=P / \sqrt{ } R_{0} E^{\prime} L^{2} h, \quad \delta^{*}=\delta \sqrt{ } R_{0} h / E^{\prime}, \quad \lambda^{*}=E^{\prime} L \lambda, \quad V_{0}^{*}=V_{0} / \dot{a}^{*}
$$

where $E^{\prime}=E$ at plane stress condition and $E^{\prime}=E /\left(1-v^{2}\right)$ in plane strain condition when $E$ and $v$ are Young's modulus and Poisson's ratio of the specimen, respectively.

To calculate the load and deflection of a circular tube in LC tests by using equ.(4), the compliance, $\lambda(a)$. of specimen with an arbitrary crack length. $a$, is needed. The compliance of curved beam with small curvature was obtained analytically $\mid 12\}$. however, it seams to be very difficult to ohtain analytically the 
compliance of tube in LC tests. In this study, therefore, the compliance was determined numerically by using two dimensional finite element method (FEM). From the calculations for various cases, it was found that $\lambda^{*}$ depends on the sizes of specimen and crack length. As the parameters representing these two sizes, the ratio of the wall-thickness to the mean radius of specimen, $h / R_{\mathrm{m}}$, and the non-dimensional crack length, $x(=a / h)$, were adopted. Fig. 2 shows $\lambda^{*}$ with various $h / R_{\mathrm{m}}$ in the range of $x=0 \sim 1$. Of cause, the compliance increases with the increase of $x$ and with the decrease of $h / R_{\mathrm{n}}$. In 3PB tests, the compliance goes up to infinity when $x=1$, i.e. the crack extends through the tube wall completely. In LC tests, however, the compliance reaches a finite value as shown in Fig.2, even after the occurrence of fracture at V-V cross-sections (see Fig.1). Because, the two half rings still keep rigidity until fracture occurs at $\mathrm{H}-\mathrm{H}$ cross-sections. Solid lines are fitting curves obtained by an equation as follows :

$$
\lambda^{*}=B_{1}\left(1+B_{2} x^{\prime \prime}\right) \quad\left(B_{1}, B_{2}, b: \text { constants }\right)
$$

For example, the curve of $h / R_{\mathrm{n}}=0.4$ has $B_{1}=37.8 . B_{2}=3.2, b=2.0$.

The relationship between $a$ and stress intensity factor, $K_{1}$, for glasses and ceramics are often expressed by a simple power law as $\dot{a}=C \cdot K_{\mathrm{l}}{ }^{n}$, where $C$ and $n$ are constants. From the relation $R=G=$ $K_{\mathrm{I}}{ }^{2} / E$, it follows that $R \propto \dot{a}^{2 / n}$. Therefore, crack-rate sensitivity parameter, $m$, can be given by $m=2 / n$ and evaluated from references[4,13], i.e. $m \approx 0.10$ for glasses and $m \approx 0.04$ for mullite ceramics.

In numerical calculations, the length and the mean radius of specimen, the compliance of testing machine and the reference crack extension rate were assumed to be $L=10 \mathrm{~mm}, R_{\mathrm{n}}=10 \mathrm{~mm}, \Lambda=0$ and $\dot{a}^{*}=10^{-5} \mathrm{~m} / \mathrm{s}$, respectively.

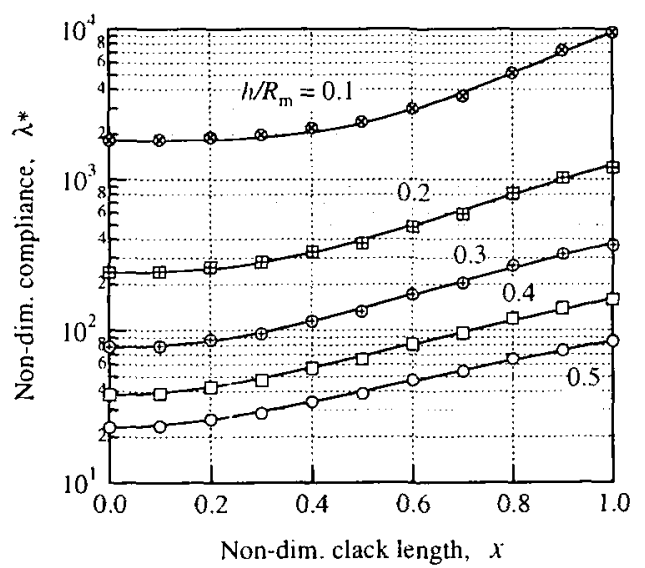

Fig. 2 Non-dimensional compliance, $\lambda *$, obtained from FEM analyses and their fitting curves.

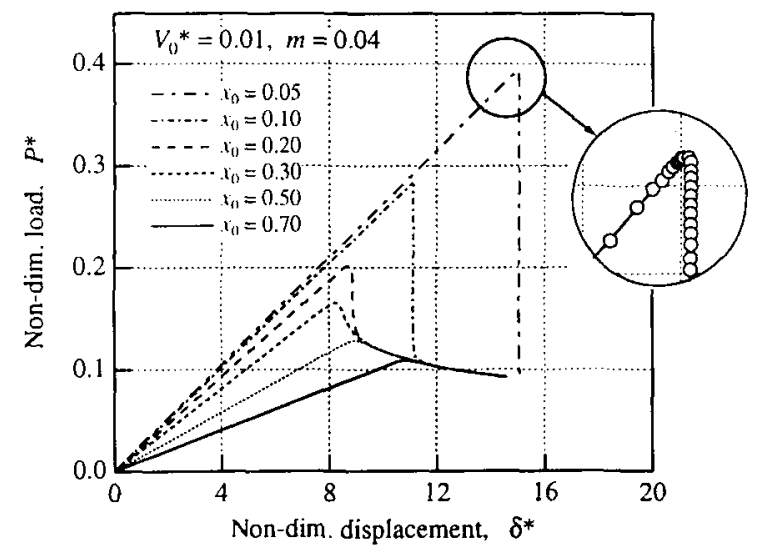

Fig.3 Load-deflection curves in lateral compression obtained with various $x_{0}$.

\section{DISCUSSIONS}

\subsection{Effects of initial crack length}

To examine the effect of initial crack length, $x_{0}\left(=a_{0} / h\right)$, a series of calculations with $m=0.04, h / R_{\mathrm{n}}=$ 0.4 and $V_{1} *=0.01$ were performed in the range of $x_{0}=0.05 \sim 0.7$. Fig. 3 shows $P-\delta$ curves obtained from linking calculated points, as shown in a circle. The maximum load, $P{ }^{*}{ }_{\max }$, and specimen rigidity decreases with the increase of $x_{1}$. In the range of $x_{0} \geq 0.3$, stable fracture occurs throughout the test, because $P^{*}-\delta^{*}$ curves are relatively smooth without sharp peak of load. When $x_{0}=0.2$, unstable fracture (vertical drop of load) occurs after $P^{*}$ nax and is arrested at about $P^{*}=0.13$ following stable fracture up to $\delta^{*} \approx 15$. The unstable drop of the load becomes large when $x_{0}$ is small. The $P^{*} \delta^{*}$ curve with $x_{0}=0.05$ has a very sharp peak and a dramatic drop of the load without any stahle region. The $x_{11}=0.3$ looks a 
boundary value between stable and unstable fracture.

The change of non-dimensional crack extension rate, $v^{*}\left(=\dot{a} / \dot{a}^{*}\right)$, during tests is shown in Fig.4. In $x_{0} \geq 0.3$, i.e. stable fracture region, the maximum rate, $\mathrm{v}^{*}$ max , is less than 10 and dull peaks are observed. In $x_{0}<0.3$, however, $v^{*}{ }_{\text {max }}$ is greater than 100 (in the data of $x_{0}=0.2$ ) and sharp peaks appear. This is quite reasonable because unstable fracture is observed in the range of $x_{0}<0.3$ in Fig.3.

To clear this fact more, the non-dimensional deflection at maximum load, $\delta^{*}{ }_{\mathrm{ph}}$, and the maximum non-dimensional crack extension rate, $v^{*}$ max , are shown with various initial crack length, $x_{0,}$, in Fig.5. The calculation condition is the same as Fig. 3 . The $x_{0}$ when $\delta^{*}{ }_{\mathrm{pk}}$ becomes minimum is $x_{0}=0.311$. When $x_{0}=$ $0.311, \mathrm{v}^{*}{ }_{\max }=9.3$ which corresponds to $\dot{a} \approx 0.1 \mathrm{~mm} / \mathrm{s}$ or $\dot{x} \approx 0.1 \mathrm{l} / \mathrm{s}$. The left side of the line of $x_{11}=$ 0.311 is the range where $\mathrm{v}^{*}{ }_{\max }$ increases with rapidly with the decrease of $x_{0}$. While, in the right side, $\mathrm{v}^{*}{ }_{\text {max }}$ is small enough to be stable fracture. Therefore, the $x_{0}$, when $\delta^{*}{ }_{\mathrm{pk}}$ is minimum, is considered to be a threshold value whether stable or unstable fracture occurs.

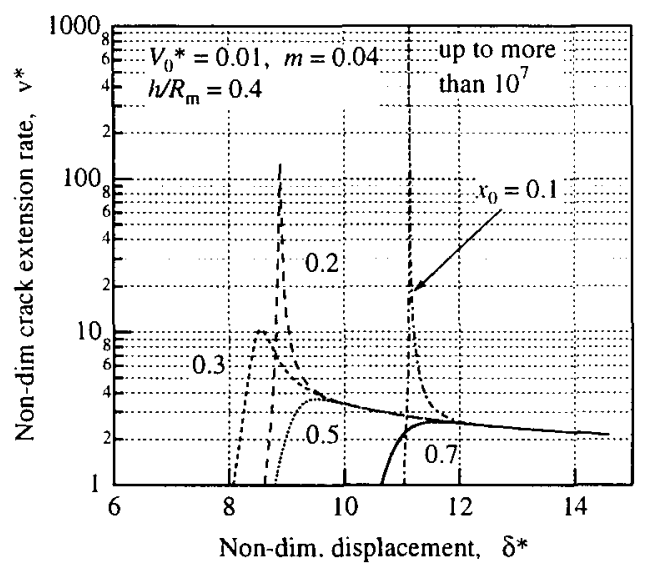

Fig.4 Non-dimensional crack extension rate, $v$, during lateral compression tests.

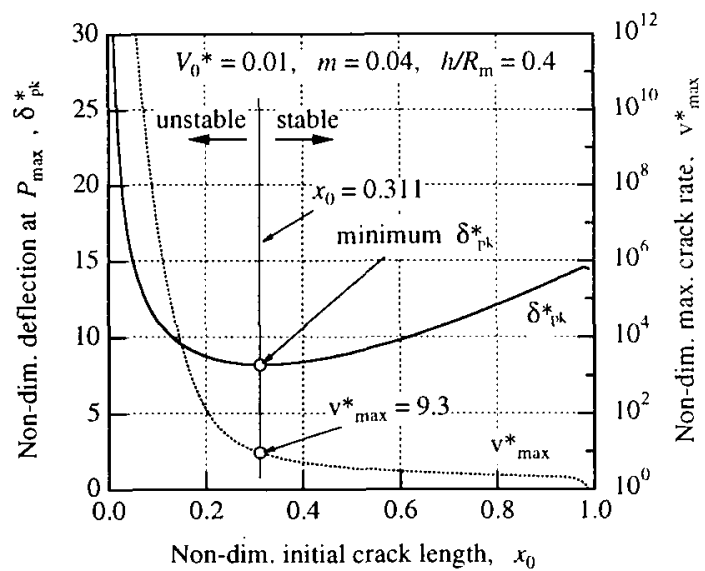

Fig.5 Non-dimensional deflection at $P_{\max }$ and maximum crack rate calculated with various $x_{0}$.

\subsection{Effect of testing velocity}

The $P-\delta$ curves and non-dimensional crack extension rate calculated with the condition of $V_{0} *=0.01 \sim$ $10^{4}$ are shown in Fig.6 and 7, respectively. Other conditions are $x_{0}=0.3, m=0.04, h / R_{\mathrm{n} 1}=0.4$, which

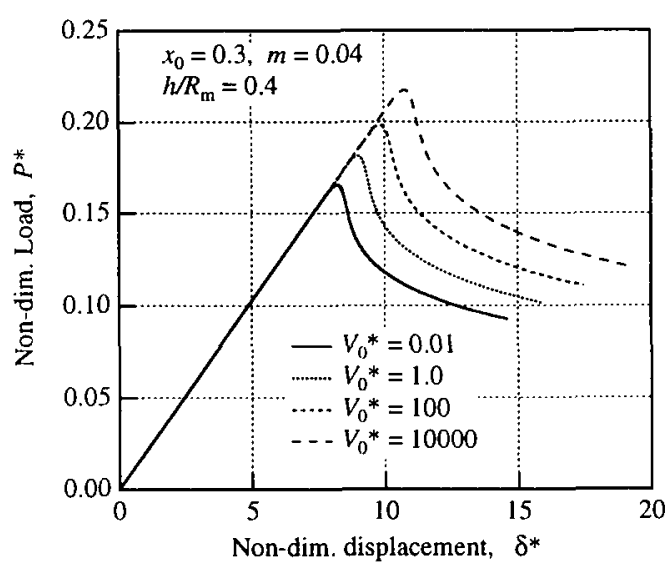

Fig.6 Load-deflection curves obtained from numerical simulations at various $V_{0}{ }^{*}$.

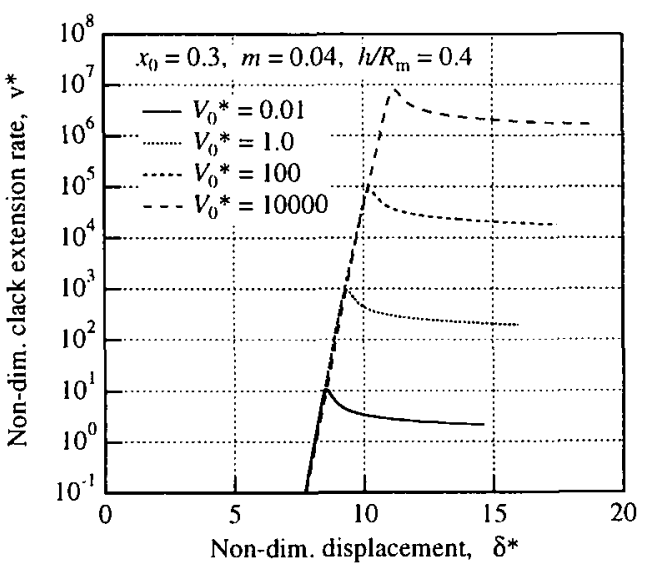

Fig.7 Non-dimensional crack extension rate, $\mathrm{v}^{*}$, obtained at various $V_{0}{ }^{*}$ 
is in stable fracture range at $V_{0}{ }^{*}=0.01$, as shown previously. The maximum load and the maximum crack extension rate increase almost proportionally with the increase of testing velocity, $V_{0}{ }^{*}$. The shape of $P^{*}-\delta^{*}$ curves and $\mathrm{v}^{*}-\delta^{*}$ curves do not change and just its level during crack extension rises by the increase of $V_{0}{ }^{*}$. This means that the $P{ }^{*}$ max depends on the testing velocity or the loading rate as long as the material is crack-rate sensitive.

Fig. 8 shows the effects of testing velocity and crack-rate sensitivity on the maximum load. The calculation condition is $x_{0}=0.01$ and $h / R_{\mathrm{n}}=0.4$. If the material is insensitive to the crack rate, i.e. $m=0$, the $P *_{\text {nlax }}$ does not depend on the testing velocity. This means that the crack-rate sensitivity of brittle materials is one of the principal reasons why the maximum load increases with the increase of testing velocity. In this figure, the maximum load ratio, $P{ }^{*}{ }_{\max } / P_{\max (1)}$, is shown by using $P^{*}{ }_{\max 0}$ which is the maximum load obtained in the condition of $m=0$. If $m \neq 0$, the $P_{\max }$ increases with the increase of $V_{0} *$ as same as Fig. 6 and the rate of the increase depends on the crack-rate sensitivity, i.e. the increase of $P^{*}{ }_{\text {max }}$ becomes larger when $m$ is large.

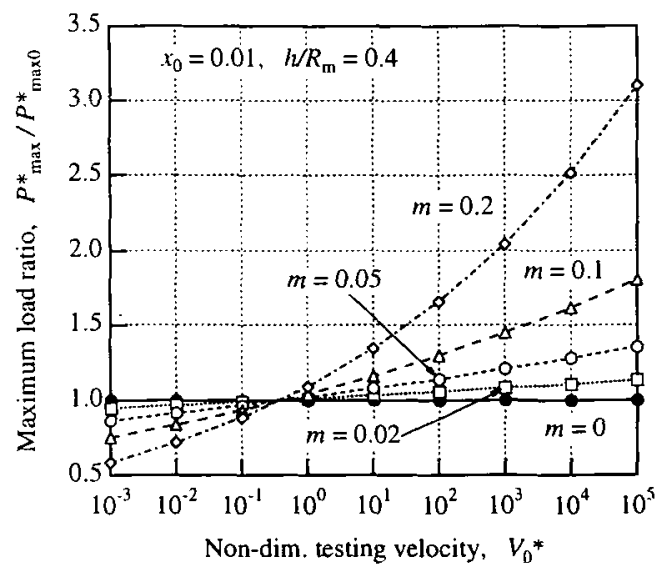

Fig.8 Effects of testing velocity and crack-rate sensitivity on maximum load.

\subsection{Comparison with experimental results}

The material tested is mullite $\left(\mathrm{Al}_{2} \mathrm{O}_{3}: 53 \mathrm{wt} . \%, \mathrm{SiO}_{2}: 41\right.$ wt.\%) ceramic tube sold on the market. The test piece has a length of $L=10 \mathrm{~mm}$, an outer diameter of $D_{\mathrm{o}}=6 \mathrm{~mm}$ and a wall-thickness of $h=1 \mathrm{~mm}$. The mechanical properties of this mullite tube is shown in Table 1, where $\sigma_{\mathrm{T}}$ is the tensile strength. Static tests were carried out by using an ordinary

Table 1 Mechanical properties and density of mullite tube.

\begin{tabular}{cccc}
\hline $\begin{array}{c}E \\
(\mathrm{GPa})\end{array}$ & $v$ & $\begin{array}{c}\sigma_{\mathrm{T}} \\
(\mathrm{MPa})\end{array}$ & $\begin{array}{c}\rho \\
\left(\mathrm{kg} / \mathrm{m}^{3}\right)\end{array}$ \\
\hline 118 & 0.25 & 90 & $2.6 \times 10^{3}$ \\
\hline
\end{tabular}
universal material testing machine at about $V_{0}=3 \times 10^{-8} \mathrm{~m} / \mathrm{s}$. Dynamic tests were performed by using a split Hopkinson pressure bar system and the testing velocity is about $V_{0}=0.6 \mathrm{~m} / \mathrm{s}$. This system is the same as that in the reference [7]. The Weibull plots of the strength obtained from the dynamic and static LC tests are shown in Fig. 8. These strength were obtained by using a convenient equation[7] which is $\sigma_{\mathrm{LC}}=$ $0.707 \times\left\{P_{\max } /\left(L D_{0}\right)\right\} \times\left(h / D_{0}\right)^{-2.1}$. The prediction of fracture probability was carried out by using medianRank method, i.e. $F_{\mathrm{i}}=(i-0.3) /(N+0.4), \quad i:$ an ordinal number, $N:$ a sample number. From this figure, the dynamic and static strength of mullite are evaluated to be $\sigma_{\mathrm{LCD}}=213 \mathrm{MPa}$ and $\sigma_{\mathrm{LCS}}=135 \mathrm{MPa}$, respectively. The ratio of the dynamic strength to the static, $\sigma_{\mathrm{LCI}} / \sigma_{\mathrm{LCS}}$, is about 1.58 .

The circular tubes used for experiments do not have any artificial cracks. However, the analysis shown above requires an initial crack to perform the calculation. In the calculation, therefore, $x_{0}=0.005$ was chosen because of the coarseness of specimen surface. This corresponds to the coarseness of $5 \mu \mathrm{m}$.

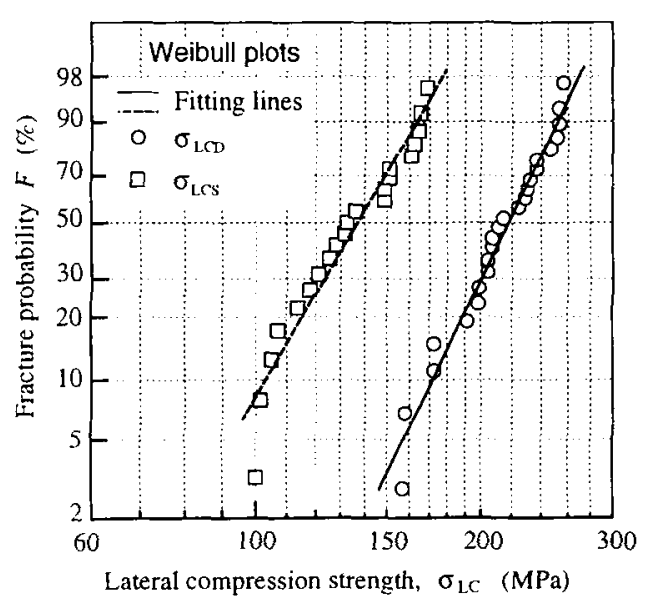

Fig.9 Weibull plots of lateral compression strength obtained from dynamic and static experiments. 
From the calculations with the dynamic and static testing velocity, the ratio of non-dimensional maximum loads, $P{ }^{*}{ }_{\max } / P{ }^{*}{ }_{\operatorname{maxs}}=1.997 / 1.436=1.39$ was obtained. This is little smaller than that estimated from experiments. This may be understood that the crack-rate sensitivity of brittle materials is not only one reason of the increase of $P_{\text {max }}$. However, it seems to be still one of main reasons.

\section{CONCLUSIONS}

In this study, the deformation of pre-cracked circular tubes of brittle materials in lateral compression tests was considered analytically by applying a numerical method taking account of crack-rate sensitivity. In applying the technique to LC tests, the compliance of pre-cracked tubular specimen with various thickness-radius ratio was estimated by using the results from two-dimensional finite element analysis. The non-dimensional compliance $\lambda^{*}$ can be approximated as a function of non-dimensional crack length $x$, i.e. $\lambda^{*}=B_{1} \cdot\left(1+B_{2} x^{\mathrm{h}}\right)$.

The effects of initial crack length and loading rate on the behaviour of circular tubes in LC tests were examined by the numerical simulations. It was found that at a static rate, stable fracture occurred all over the test in the specimen with relatively large initial cracks. On the contrary, the specimen with small initial cracks shows totally unstable fracture throughout the tests. The $x_{0}$, when the deflection at $P_{\max }$ is minimum, is considered to be a threshold value whether stable or unstable fracture occurs.

If a perfectly brittle material is sensitive to the crack extension rate, the maximum load depends on the testing velocity, i.e. $P_{\max }$ increases with the increase of $V_{0}$. In addition, the rate of the increase becomes large when the crack-rate sensitivity is large. From the comparison with experimental results, it was also found that the crack-rate sensitivity is one of the most principal reasons of the increase of $P_{\text {max }}$, although it could not cover all.

\section{References}

[1] Wiederhorn S.M., J.Ame. Ceram. Soc. 50 (1967) 407-414.

[2] Evans A.G., J. Mater. Sci. 7 (1972) 1137-1146.

[3] Freiman S.W., Mulville D.R. and Mast P.W., J. Mater. Sci. 8 (1973) 1527-1533.

[4] Wiederhorn S.M., Fracture Mechanics of Ceramics, vol.2, (Plenum Press, New York, 1974) pp. 613-648.

[5] Nojima T., "Crack satbility in rate sensitive ceramics and their rate dependence", Proc. of Euro DYMAT 94, Oxford 26-30 September 1994 , J. Harding Ed. (Les Éditions de Physique, Les Ulis, 1994) pp.C8-689-694.

[6] Nojima T. and Nakai O., J.Soc. Mat.Sci. Japan, 42, (1993) 969-975.

[7] Kobayashi H.Daimaruya M. and Nojima T., J.Soc. Mat.Sci. Japan, 45, (1996) 310-315.

[8] Nojima T. and Tsuyoshi H, J.Soc. Mat.Sci. Japan, 44, (1995) 445-450.

[9] Reid S.R. And Reddy Y.T., Int. J. Solids Struct. 14 (1978) 213-225.

[10] Kobayashi H. and Daimaruya M.,"Dynamic and quasi-static lateral compression tests of ceramic tubes" Proc. of Euro DYMAT 94, Oxford 26-30 September 1994, J. Harding Ed. (Les Éditions de Physique, Les Ulis, 1994) pp.C8-275-280.

[11] Nojima T. and Ogawa K., "Impact strength of ceramics at high temperatures", Int. Conf. Mech. Prop. Materials at High Rates of Strain( Int. Phys. Conf. Ser. No. 102), Oxford, 1989, J. Harding Ed. Pp.371-378.

[12] Tracy P.G., Engng. Fract. Mech. 7 (1975) 253-260.

[13] Yamade Y., Kawaguchi Y., Takeda N. and Kishi T., "Effect of defects and grain size on strength of mullite ceramics", Fract. Mech. Ceram., B.C. Bradt et al Eds. (Plenum Press, New York, 1992) pp.291-306. 